\title{
Aspleniaceae endémicas del Perú
}

Blanca León ${ }^{1,2}$

${ }^{1}$ Museo de Historia Natural, Av. Arenales 1256, Aptdo. 14-0434, Lima 14, Perú

2 Plant Resources Center, University of Texas at Austin, Austin TX 78712 EE.UU.

blanca.leon@mail.utexas.edu

\section{Resumen}

Esta familia es reconocida en el Perú con un solo género, Asplenium y más de 65 especies (Tryon \& Stolze, 1993; Smith et al., 2005). Aspleniaceae está representada en un amplio rango de ambientes; sin embargo, las dos especies endémicas reconocidas ocupan principalmente los bosques de las regiones del Bosque Húmedo Montano y Premontano, entre los 700 y $2500 \mathrm{~m}$ de altitud. Solamente, una de estas especies cuenta con poblaciones en un área protegida.

Palabras claves: Aspleniaceae, Perú, endemismo.

\section{Abstract}

This family is recognized in Peru by the genus Asplenium and more than 65 species (Tryon \& Stolze, 1993; Smith et al., 2005). The Aspleniaceae is represented in a wide range of environments; however the two endemic species are known mainly to occur in the Humid Montane and Premontane Forests regions, between 700 and $2500 \mathrm{~m}$ elevation. Only one species is represented in a protected area.

Key words: Aspleniaceae, Peru, endemism.

\section{Asplenium divaricatum Kunze}

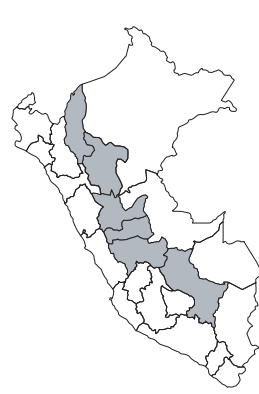

\section{LC}

Publicación: Linnaea 9: 71. 1834.

Colección tipo: E.F. Poeppig s.n.

Herbarios: B, BM, NY, P, W.

Nombre común: Desconocido.

Registro departamental: AM, CU, HU, JU, PA, SM.

Regiones Ecológicas: BMHM, BMHP, BHA; $700-2400 \mathrm{~m}$.

SINANPE: PNTM

Herbarios peruanos: USM (1).

Observaciones: Helecho terrestre, conocido de varias localidades aisladas, en las cuencas del Utcubamba, Huallaga y Tulumayo. Esta especie se conoce de poblaciones en lugares abiertos, como laderas con rocas cálcicas y matorrales modificados.

\section{Asplenium projectum Kunze}

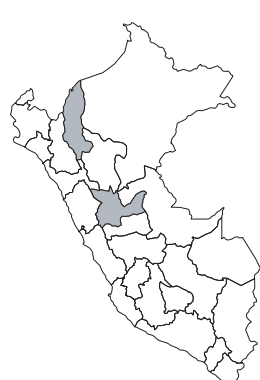

\section{EN, B1a}

Publicación: Linnaea 9: 68. 1835.

Colección tipo: E.F. Poeppig s.n.

Herbarios: B, P.

Nombre común: Desconocido.

Registro departamental: AM, HU.

Regiones Ecológicas: BMHM; $2500 \mathrm{~m}$.

SINANPE: Sin registro.

Herbarios peruanos: Ninguno.

Observaciones: Helecho terrestre que pertenece al grupo de Asplenium perwiranum. El porte reducido y hábitat podrían contribuir a la poca recolección de esta especie y su representación en las colecciones de herbario, siendo la más reciente de 1963. Conocida de dos localidades, distantes entre ellas por más de $300 \mathrm{~km}$. Esta especie habita áreas abiertas, en la zona del bosque montano húmedo; esta zona está sujeta a deforestación intensa. 